\title{
Article
}

\section{Multiple methods of monitoring cats at a landscape-scale}

\author{
Cheryl A. Lohr' ${ }^{1}$, Kristen Nilsson ${ }^{1}$, Ashleigh Johnson ${ }^{1}$, Neil Hamilton ${ }^{1}$, Mike Onus $^{1}$ and Dave Algar ${ }^{1}$
}

${ }^{1}$ Biodiversity Conservation Science, Department of Biodiversity, Conservation and Attractions, 17 Dick Perry Avenue, Kensington, Western Australia 6151

\begin{abstract}
Feral cats are both difficult to manage and harder to monitor. We analysed the costefficacy of monitoring the pre- and post-bait abundance of feral cats via camera-traps or track counts using four years of data from the Matuwa Indigenous protected Area. Additionally, we report on the recovery of the feral cat population and the efficacy of subsequent Eradicat ${ }^{\circledR}$ aerial baiting programs following 12 months of intensive feral cat control in 2019 that consisted of aerial baiting and leg-hold trapping. Significantly fewer cats were captured in $2020(n=8)$ compared to $2019(n=126)$. Pre-baiting surveys for 2020 and 2021 suggested that the population of feral cats on Matuwa was very low, at 5.5 and 4.4 cats $/ 100 \mathrm{~km}$ respectively, which is well below our target threshold of 10 cats/100 km. Post-baiting surveys then recorded 3.6 and 3.0 cats/100 km respectively, which still equates to a $35 \%$ and $32 \%$ reduction in cat activity. Track counts recorded significantly more feral cats than camera traps and were cheaper to implement. We recommend that at least two methods of monitoring cats be implemented to prevent erroneous conclusions.
\end{abstract}

Keywords: feral cat; Felis catus; Australia; Indigenous Protected Area; 1080

\section{Introduction}

Feral cats (Felis catus), cats that live in the wild and can survive without human reliance or contact, are recognised as a key threatening process to native species in Australia [1-3] and around the world [4,5]. Predation by feral cats has been demonstrated to threaten the persistence of many native species [6,7], and causes billions of dollars damage to the natural and agricultural environment [8] alongside disease transmission [9]. Predation by feral cats has been identified as one of the major obstacles to the successful reintroduction of extirpated native fauna [10-13]. Therefore, the suppression of feral cat populations is a critical component to the successful conservation of small to medium-sized native fauna [14,15].

While implementing methods of feral cat control is difficult; measuring the outcomes of feral cat control, the pre- and post-management abundance of cats, is harder. Detecting feral cats is difficult because they are a cryptic species that avoids interactions with humans [16] and in some environments cannot be readily detected via remote sensing technologies, such as camera-traps, despite the use of lures $[17,18]$. Estimating the abundance of an animal species typically requires capturing or identifying individual animals on multiple occasions [19]. Capturing feral cats on multiple occasions is extremely difficult, requiring the use of multiple labour intensive techniques [20] and feral cats frequently lack the unique markings required to identify individuals for mark-resight analysis [21].

Feral cat control is primarily a task performed or funded by government agencies [1]. Between 1998 and 2003, \$4.7 million was spent on labour associated with cat control with operational costs (materials, vehicles, equipment) requiring additional funding [22]. From an economic perspective, it is essential that we measure the outcomes of the pre- and postmanagement abundance of cats. Cats can breed rapidly [23], and disperse over long distances $[24,25]$, which allows populations of feral cats to potentially recover quickly post- 
management. Moseby et al. [26] demonstrated that some fauna can survive and increase in abundance in the presence of a low density of cats $\left(\sim 0.5 \mathrm{~km}^{2}\right)$. From a biological perspective, it is essential that consistent and on-going monitoring of the pre- and post-management abundance of cats occurs to ensure we maintain a low density of cats.

The challenge is to develop a cost-effective method of monitoring cats at a landscapescale. Several recent studies have tested the efficacy of camera-traps with slight modifications to camera placement, lures, and survey duration with minor improvements in the efficacy of camera-traps [17,27-29]. Edwards et al. [30] compared track counts with spotlighting and concluded that track counts were a more reliable method of monitoring mammalian carnivores. These studies did not consider the cost of implementing these techniques. Lohr and Algar [31] used both camera-traps and track counts to monitor feral cats and concluded that camera-traps provide more reliable data but are considerably more expensive and time-consuming to implement than track counts. Track counts provide a relatively cheap, rapid survey technique but is susceptible to error from inexperienced observers, and unfavourable weather conditions erasing tracks. Lohr and Algar [31] did not formally analyse the cost-efficacy of these two techniques.

The purpose of this manuscript is to analyse the cost-efficacy of monitoring the preand post-bait abundance of feral cats via camera-traps or track counts. Additionally, we report on the recovery of the feral cat population and the efficacy of subsequent Eradicat $\AA$ aerial baiting programs on the Matuwa Indigenous Protected Area (IPA) following 12 months of intensive feral cat control [31] that consisted of aerial baiting and landscapescale leg-hold trapping.

\section{Materials and Methods}

\subsection{Study site}

The Rangelands Restoration program at the Matuwa Indigenous Protected Area $\left(2,440\right.$ km²; ex-Lorna Glen pastoral lease) in central Western Australia $\left(26^{\circ} 13^{\prime} \mathrm{S}, 121^{\circ} 33^{\prime}\right.$ E; Figure 1) aims to achieve the successful reconstruction and conservation of Australian arid zone native species diversity. To date, five species have been successfully reintroduced to Matuwa; the bilby (Macrotis lagortis), common brushtail possum (Trichosurus vulpecula hypoleucus), Barrow Island golden bandicoot (Isoodon auratus barrowensis), burrowing bettong (Bettongia leseuer), and mala (Lagorchestes hirsutus), of which the final two are still confined to a predator-free fenced area [32-35]. The successful reintroduction of native species to the open landscape can only be maintained if an effective, sustained feral cat control can be achieved [10,36-38].

Matuwa consists of two main land systems: (1) Bullimore-sand plains and dunes dominated by spinifex (Triodia spp.); and (2) Sherwood-breakaways and stony plains dominated by mulga and other acacia shrublands with the most common vegetation unit being mulga (Acacia aneura) and Eucalyptus kingsmillii over hummock grasslands (Triodia basedowii) [39,40]. Matuwa, being in the arid zone, is characterized by extreme temperatures and low and erratic rainfall with the annual average of $261.7 \mathrm{~mm}$ (Bureau of Meteorology, records 1898-2018; weather station No. 13012 located in Wiluna, Western Australia $137 \mathrm{~km}$ WSW of Matuwa). Average maximum daily temperatures range from 19.5 ${ }^{\circ} \mathrm{C}$ in winter to $38^{\circ} \mathrm{C}$ in summer and average minimum temperatures range from $5.4{ }^{\circ} \mathrm{C}$ in winter to $23.0^{\circ} \mathrm{C}$ in summer.

\subsection{Feral cat management}

Since 2003, we have been using the poison bait known as Eradicat $₫$ on Matuwa to control feral cats $[36,41,42]$. Eradicat $®$ baits contain $4.5 \mathrm{mg}$ of directly injected toxin ' 1080 ' (sodium monofluoroacetate). Prior to being laid, feral cat baits are thawed in direct sunlight and sprayed, with an ant deterrent compound (Coopex®) at a concentration of 12.5 $\mathrm{g} / \mathrm{L}$. This process is aimed at reducing bait degradation by ant attack and maintaining the palatability of the bait to cats. Most years, baits are deployed from a fixed wing aircraft at 
a rate of 50 baits $/ \mathrm{km}^{2}$ during the cool, dry winter periods when the abundance and activity of all prey types is at its lowest [42]. Since Matuwa is a site subject to adaptive management [31] there has been some variation in the portion of Matuwa subject to aerial baiting and/or ground based baiting. Hence, for this analysis we have selected data from feral cat survey points that occurred on portions of Matuwa subject to aerial baiting only between 2018 and 2021 (minimum 1,353 $\mathrm{km}^{2}$ ).

Three feral cat trapping programs were conducted at Matuwa between $2018-2020$. The first, a small-scale exercise with 1,600 trap-nights, was conducted immediately following the baiting program in August 2018 to provide a snapshot of the population demographic of resident cats that had survived the baiting program [31]. The second, a more comprehensive trapping program with the goal of reducing the abundance of feral cats on Matuwa and a total of 5,398 trap-nights was conducted across the site prior to the baiting program in March and April 2019 [31]. The third trapping program, which is first published here, was conducted from 5 August to 6 September 2020, with each trap in commission for 10 consecutive days as per previous years (Figure 1). The whole trapping circuit, comprised of a linear track length of $280 \mathrm{~km}$. The three trapping programs used the same personnel and trapping methodology. Trap locations recorded in 2019, using a Garmin GPS Rhino 650 (Garmin Ltd., Olathe, Kansas, U.S.A.), were used to re-position trap-sets in 2020. Of the 573 trap-sets deployed in 2019, 558 trap-sets were recommissioned in 2020. Fifteen trap sites were discontinued because of access difficulty along one track in the southeast corner of the property (Figure 1). Trapped cats were euthanased using a 0.22 calibre rifle shot to the head at point blank range. Chi-squared tests were performed on the trapping data to test whether there were significant differences in captures between the two trapping programs. 


\section{Legend}

- 2021 track transects

2020 track transects

2019 track transects

2018 track transects

[8] 130 camera-traps

120 camera-traps

2019 cat traps

i. Traps no cat

2020 cat traps

- Traps no cat

cat

4WD tracks

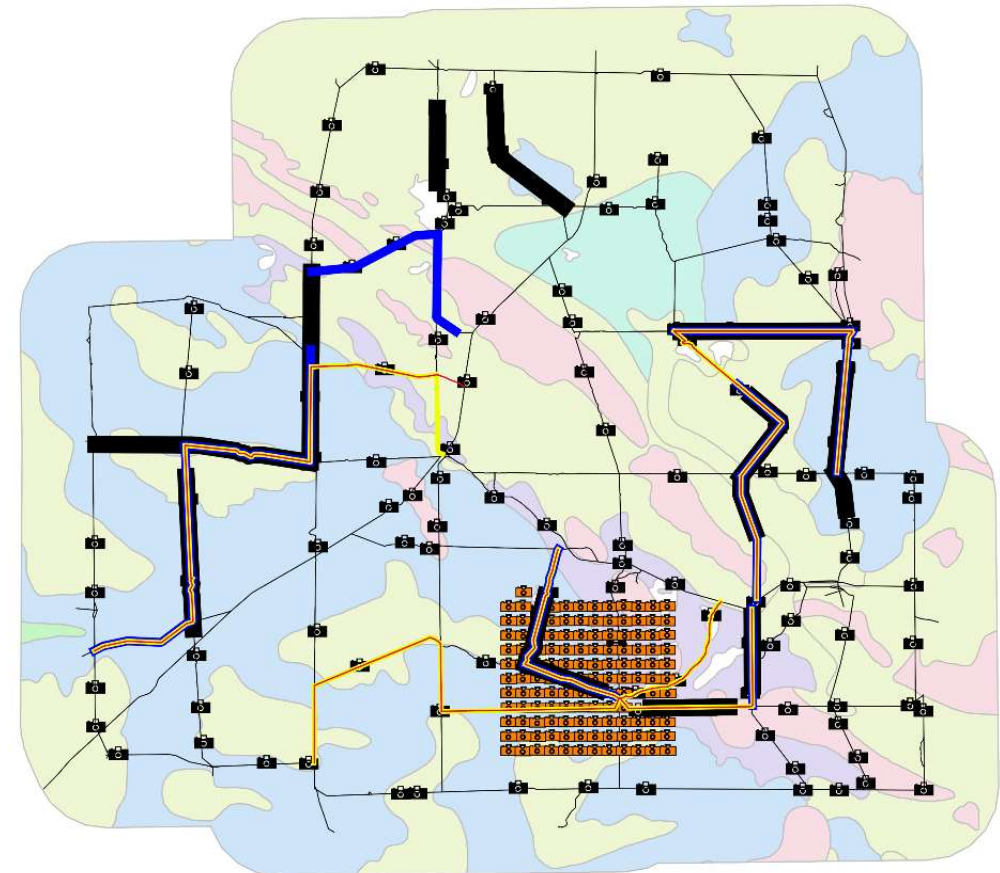

\section{Vegetation}

Hummock grassland

Mulga woodlands

Saline areas with Tecticornia spp.

Mixed shrubland

Eucalyptus spp., Melaleuca spp.,
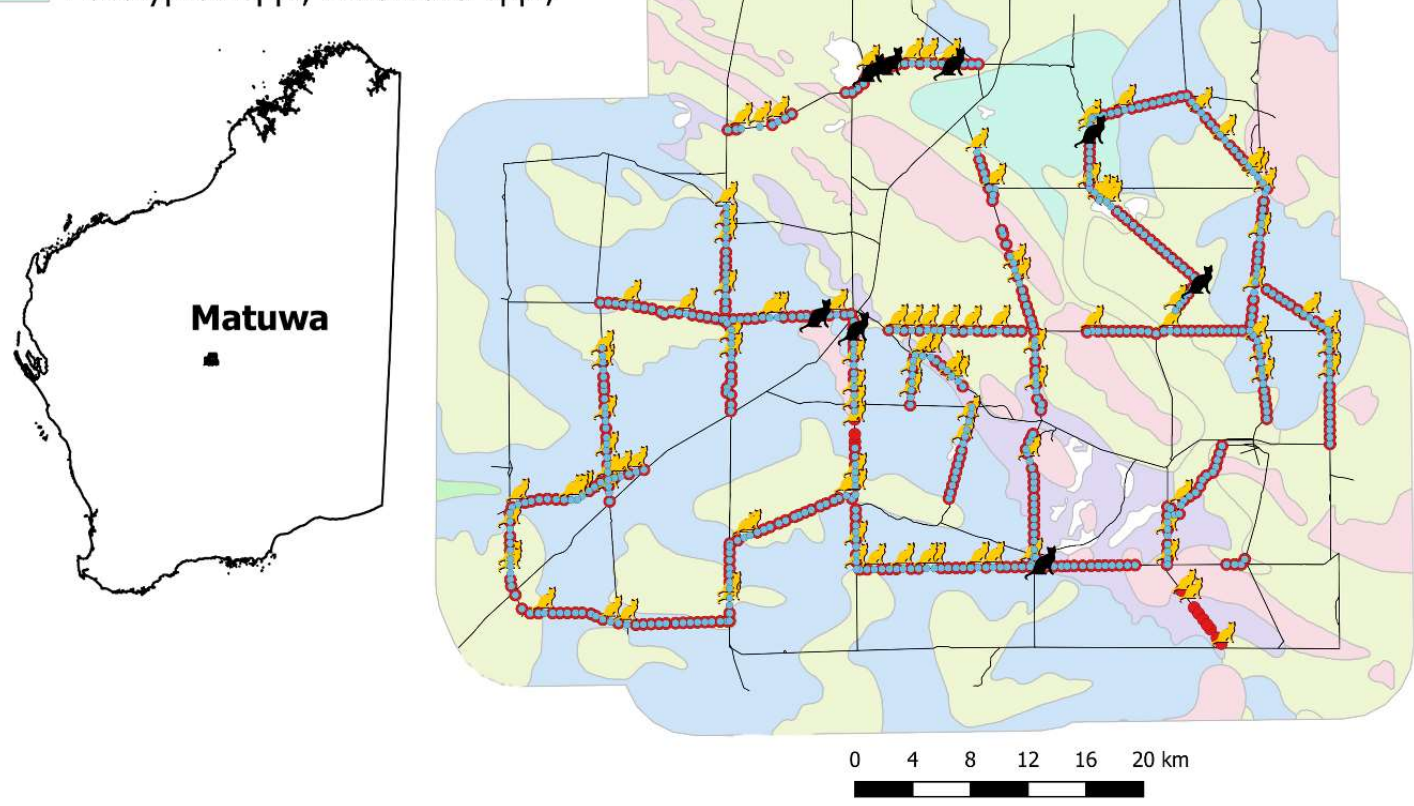

Figure 1. Maps of the feral cat monitoring (top) and trapping (bottom right) between 2018 and 2021 on the Matuwa Indigenous Protected Area in central Western Australia (bottom left). 


\subsection{Feral cat demographics}

All animals captured were sexed and weighed; a broad estimation of age (as either kitten, juvenile or adult) was recorded using weight as a proxy for age. The yearling weight/age classes adopted in the previous study (see Table 1; adapted from Jones and Coman [43]) were used to define the population age structure at that capture time. The pregnancy status of females was determined by examining the uterine tissue for embryos.

Table 1. The weight groups for the cat age classes of the trapped population.

\begin{tabular}{ccc}
\hline Category & Male & Female \\
\hline Kitten & $<1.0 \mathrm{~kg}$ & $<1.0 \mathrm{~kg}$ \\
Juvenile & $1.0<3.0 \mathrm{~kg}$ & $1.0<2.5 \mathrm{~kg}$ \\
Adult $1-2$ years of age & $3.0-4.0 \mathrm{~kg}$ & $2.5-3.0 \mathrm{~kg}$ \\
Adult $>$ 2 years of age & $4.0+\mathrm{kg}$ & $3.0+\mathrm{kg}$ \\
\hline
\end{tabular}

\subsection{Camera-trap monitoring}

Two camera-trap arrays were used to monitor feral cat activity on Matuwa pre- and post-management. In 2018 - 2020, 120 camera-traps (Reconyx PC900 Hyperfire Professional Covert camera; Reconyx, Wisconsin, U.S.A.) were installed using a stratified-random design based on the 20 most common geological types in the Wiluna region [44]. The cameras were placed between $30 \mathrm{~m}$ and $200 \mathrm{~m}$ away from an ungazetted track (Figure 1). Camera-traps were, on average, $2.80 \mathrm{~km}$ from their nearest neighbour $(\min =0.97 \mathrm{~km}$, max $=5.92 \mathrm{~km}$ ). Spatial autocorrelation is very unlikely at this scale [45] despite the potentially large home-ranges of feral cats [46]. Data from 70 of these cameras that were placed in an aerial baited site in 2018 and 2019 were used in subsequent analysis [31]. In 2020 and 2021, the entirety of Matuwa was aerial baited. Data from all 120 cameras in 2020 were used. In 2020 - 2021, a grid of 130 camera-traps with cameras spaced $1 \mathrm{~km}$ apart was installed on Bullimore sandplain in the south of Matuwa (Figure 1). Previous research has shown that feral cats are most active on sandplains [31].

All cameras were mounted on a $30 \mathrm{~cm}$ high plastic sand peg, facing south, with the aperture parallel to ground, in a space with at least $3 \mathrm{~m}$ of open ground in front of the camera. Two olfactory lures (Catastrophic and Canines-a-plenty from Outfoxed Pest Control, Victoria, Australia) were placed on two natural sticks approximately $30 \mathrm{~cm}$ tall and 1 $\mathrm{m}$ apart, $3 \mathrm{~m}$ from the front of the camera and refreshed at least 10 days before and after management. Herbaceous vegetation was removed if present immediately in front of the camera. Camera-traps were programmed to capture three photos per trigger, with no quiet period. Timed photos were also taken at $23: 00 \mathrm{~h}$ to monitor the quality of photos and operation of the camera.

The efficacy of the lures is thought to fade over time. Therefore, we used data from the first 10 days after camera-traps and lures were set, pre- and post-management. Photos were stored in the Colorado Parks and Wildlife Photo Warehouse database (CPW) [47]. All photos of feral cats were viewed by at least two observers to confirm species identification. To minimise temporal autocorrelation, we grouped consecutive photos if they were $<5$ min apart and used these sequences as independent records for subsequent analysis [48].

\subsection{Track counts}

Track counts collect data that reflects that activity of feral cats on unsealed roads referred to as the track activity index (TAI). Approximately two weeks pre- and post-baiting, two teams of experienced observers ran a single TAI transect at least $50 \mathrm{~km}$ in length each day $[31,36]$ for four consecutive days (Figure 1). Teams alternated transects each day to reduce observer bias. Since Matuwa is a site subject to adaptive management [31] there 
has been some variation in the placement of TAI transects between years (Figure 1) but the placement of TAI transects is consistent within years pre- and post-cat management.

TAI-transects occur on sandy 4WD tracks, which are initially cleared of any animal tracks by towing a heavy iron drag behind a 4WD vehicle. Observers, driving all-terrain vehicles (ATVs) at a speed of 10-15 km/h then inspect the tracks for cat tracks, $1 \mathrm{~h}$ after sunrise, and clear new signs of animal activity by towing a light-weight chain iron drag. To minimise spatial autocorrelation cat tracks that occur within $1 \mathrm{~km}$ radius of one another on a daily survey are aggregated into one cat detection. The single $50 \mathrm{~km}$ transect is split at disused wells and intersections with any observations recorded within $1 \mathrm{~km}$ of the well or intersection being discarded. The number of cats observed on each TAI-transect is scaled against the total length of the TAI-transect within each day and then averaged across sequential survey days. Only TAI-transects that occurred on areas that were aerially baited with Eradicat ${ }^{\circ}$ were analysed.

\subsection{Analysis of monitoring data}

Camera-trap and TAI data were analysed via negative binomial mixed-effects models in the package glmmTMB [49], with monitoring method (dispersed camera-traps, grid camera-traps, or track count), survey (pre- or post-management and post-trapping), and year as fixed effects, while year and TAI-transect name or camera ID were used as random effects. Models were compared via Akaike's Information Criterion (AICc) in the package AICcmodavg 2.3-1 [50].

\section{Results}

\subsection{Feral cat demographics}

The 2020 trapping program which was conducted over 5,539 trap-nights, resulted in the capture of eight cats ( 5 males, 3 females). A number of the 558 traps were decommissioned early when they captured non-target species such as dingo/wild dog hybrids (Canis familiaris), or when red kangaroos (Osphranter rufus) and euros (O. robustus erubescens) destroyed the trap-set. Percentage trap success was 0.14 cats/trap-night; capture locations are presented in Figure 1. No kittens or juvenile cats were captured. There was no significant difference between adult male captures and adult female captures $\left(\mathrm{Chi}^{2}=0.5, \mathrm{df}=1\right.$, $P>0.50$ ). Two of the adult males were $2+$ years of age (weights 4.3 and $4.6 \mathrm{~kg}$ ) and the remaining were adults $1-2$ years of age with mean a mean weight of $3.6( \pm$ S.E. 0.3$) \mathrm{kg}$, range $3.1-3.9 \mathrm{~kg}$. The three females captured were all adults $1-2$ years of age with a mean weight of $2.8( \pm$ S.E. 0.1$) \mathrm{kg}$, range $2.8-2.9 \mathrm{~kg}$. None of the trapped females were pregnant.

Assuming equal trappability between years, there was a significant difference in the numbers of cats trapped with greater numbers in $2019(\mathrm{n}=126)$ compared to $2020(\mathrm{n}=8$, $\mathrm{Chi}^{2}=103.9, \mathrm{df}=1, P<0.001$ ), despite 141 fewer trap-nights (Figure 2). Similarly, more cats were trapped along the same trap-lines used during the pilot study of $2018(\mathrm{n}=33)$ than at the same time of year in $2020(\mathrm{n}=1)$. This was a significant difference $\left(\mathrm{Chi}^{2}=20.17, \mathrm{df}=\right.$ $1, P<0.001$ ), with a percentage trap success of 1.87 cats/trap-night in 2018 compared to 0.08 cats/trap-night in 2020. 


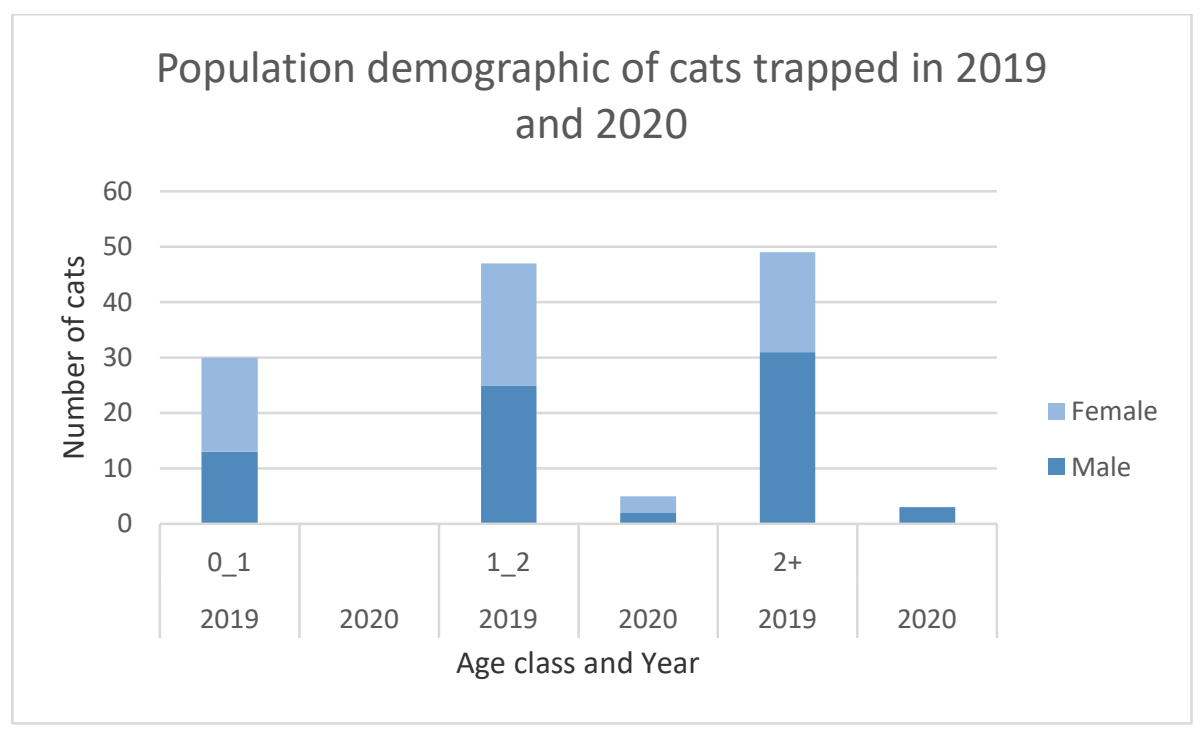

Figure 2. Sexes and age classes of the captured cats captured in 2019 and 2020.

\subsection{Monitoring feral cats}

The negative binomial mixed effects models revealed that the various arrangements of the cameras did not provide significantly different results $(P=0.89$; Table 2; Model 2; Online Supplementary Information), so we pooled data from the two camera arrays resulting in 120 cameras being deployed in 2018 and 2019, 250 cameras in 2020, and 130 cameras in 2021. The 130 cameras used in a grid array in 2021 were placed in spinifex sandplain habitat, which consistently recorded the greatest number of cats in prior studies [31]. From our best model (Table 2; Model 1) the TAI did record significantly more cat detections than cameras (estimate $=11.3, P<2.00^{-16}$; Figure 3 ). Year significantly affected the number of cats detected with pairwise comparisons revealing that 2018 recorded significantly more cats than $2020\left(P=5.20^{-3}\right)$ or $2021\left(P=5.10^{-3}\right)$. This result confirms that the second comprehensive trapping program for feral cats in March and April 2019 (prior to pre-baiting survey of 2019) significantly reduced the on-going detection of feral cats on Matuwa. The average number of feral cat detections during the pre-baiting survey was significantly higher than post-baiting surveys $\left(P<1.00^{-4}\right)$ and post-trapping surveys $(P<$ $\left.1.00^{-4}\right)$. The difference between post-baiting and post-trapping surveys was not significantly different $(P=0.52)$. The proportion of camera-traps or TAI-transects that recorded zero cats was considerable with $65 \%$ of TAI transects, $99 \%$ of cameras spread across the landscape, and $99.8 \%$ of cameras in the grid recording zero cats each day.

In 2020 and 2021, pre-baiting surveys suggested that the population of feral cats on Matuwa was very low, at 5.5 and 4.4 cats $/ 100 \mathrm{~km}$ respectively, which is well below our target threshold of 10 cats $/ 100 \mathrm{~km}$ [31]. Post-baiting surveys then recorded 3.6 and 3.0 cats $/ 100 \mathrm{~km}$ respectively, which still equates to a $35 \%$ and $32 \%$ reduction in cat activity in 2020 and 2021. Considerably more cats were detected in 2018 prior to the second comprehensive trapping program for feral cats in March and April 2019 potentially inflating the statistical significance of year and survey. Re-analysing data from 2020 and 2021 only, using model 1 (Table 2) reveals on-going significant difference between the pre-baiting and post-baiting surveys $\left(P=4.33^{-3}\right.$; Figure 3$)$, despite the initial low abundance of cats.

The feral cat detection rate for track counts was 5 to 25 times higher than the average detection rate for camera-traps. This difference may be masking the value of camera-trap data in statistical analysis. Re-analysing data from camera-traps only reveals similar results to previous models with similar results between camera arrays $(P=0.89)$, significant difference between detections in 2018 and subsequent years $(P<0.03)$ and on-going significant difference between the pre-baiting and post-baiting surveys $\left(P=6.57^{-4}\right.$; Figure 3 ). 
The 10-day camera-trap survey in the post-baiting period of 2021 detected zero cats, as did the post-trapping survey of 2020, which may lead to erroneous conclusions. The camera-trap data also suggest that the number of cat detections increased in 2018 following trapping, whereas track-counts suggested the opposite trend (Figure 3).

Table 2. Correct Akaike's Information Criterion (AICc) results for negative binomial models of cat detections by cameratraps and track counts at Matuwa between 2018 and 2021.

Model parameters are: $\mathrm{I}$ = integer count of cat detections; $\mathrm{M}=$ pooled methods of detection (camera-trap or track count); $\mathbf{m}=$ unpooled methods of detection (dispersed camera-traps, grid camera-traps, or track count); $\mathrm{S}=$ survey period (prebaiting, post-baiting, or post-trapping); $\mathrm{Y}=$ Year; $\mathrm{L}=$ Location (camera ID or TAI-transect). Parameters in brackets are random effects.

\begin{tabular}{ccccccc}
\hline Model & Parameters & K & AICc & Delta_AICc & AICcWt & LL \\
\hline 1 & $\mathrm{I} \sim \mathrm{M}+\mathrm{S}+\mathrm{Y}+(1 \mid \mathrm{Y} / \mathrm{L})$ & 10 & 3525.68 & 0 & 0.69 & -1752.83 \\
2 & $\mathrm{I} \sim \mathrm{m}+\mathrm{S}+\mathrm{Y}+(1 \mid \mathrm{Y} / \mathrm{L})$ & 11 & 3527.66 & 1.98 & 0.26 & -1752.82 \\
3 & $\mathrm{I} \sim \mathrm{m}+\mathrm{S}+(1 \mid \mathrm{Y} / \mathrm{L})$ & 8 & 3531.1 & 5.42 & 0.05 & -1757.54 \\
4 & $\mathrm{I} \sim \mathrm{M}+\mathrm{S}+(1 \mid \mathrm{Y} / \mathrm{L})$ & 7 & 3535.74 & 10.06 & 0 & -1760.86 \\
5 & $\mathrm{I} \sim \mathrm{m}+\mathrm{S}+\mathrm{Y}+(1 \mid \mathrm{L})$ & 10 & 3649.98 & 124.3 & 0 & -1814.98 \\
6 & $\mathrm{I} \sim \mathrm{M}+\mathrm{S}+\mathrm{Y}+(1 \mid \mathrm{L})$ & 9 & 3653.65 & 127.97 & 0 & -1817.82 \\
7 & $\mathrm{I} \sim \mathrm{M}+\mathrm{S}+(1 \mid \mathrm{Y})+(1 \mid \mathrm{L})$ & 7 & 3676.17 & 150.49 & 0 & -1831.08 \\
8 & $\mathrm{I} \sim \mathrm{M}+\mathrm{S}+(1 \mid \mathrm{L})$ & 6 & 3715.77 & 190.09 & 0 & -1851.88 \\
9 & $\mathrm{I} \sim \mathrm{M}+\mathrm{S}+\mathrm{Y}$ & 8 & 3815.38 & 289.7 & 0 & -1899.68 \\
\hline
\end{tabular}

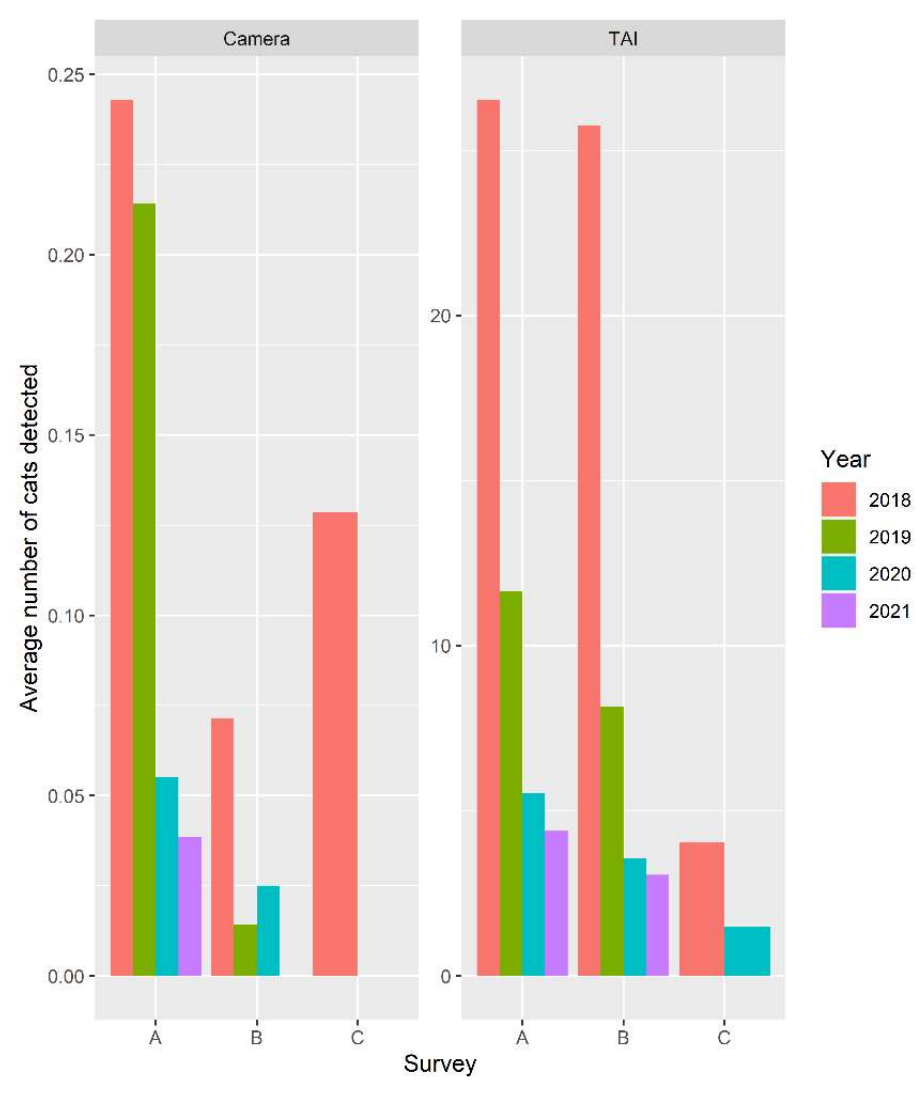

Figure 3. Average number of feral cats detected on Matuwa via camera-traps and track counts (TAI-transects). Survey notation: 'A' = pre-baiting survey; 'B' = post-baiting survey; 'C' = post-trapping survey, which occurred in August 2018 and August 2020. 


\subsection{Cost}

Feral cat monitoring on Matuwa is a long-established project. Table 3 illustrates the cost of initiating either TAI-transects or camera-trap monitoring on a new site for four years in 2021 with salary calculated as the average hourly rate of the people involved in monitoring on Matuwa. We do not include travel costs, analysis, or overtime benefits as these are site, project, and employee specific. We assume that a feral cat management project would only use one camera array. Ultimately, implementing camera-traps is twice as expensive as track counts for detecting feral cats (Table 3).

Table 3. Cost of monitoring feral cats.

\begin{tabular}{ccccc}
\hline Project & Item & \# Units & \$/Unit & Total \$ \\
\hline & Reconyx cameras and accessories & 125 & 1,000 & 125,000 \\
Camera-traps & Lure & 8 & 35 & 280 \\
& Field work, 8 surveys, 14 trips to install/remove of cameras, 5 & 1,120 & 48 & 53,760 \\
& days, 2 people & 52 & 48 & 2,496 \\
\hline Total & Photo ID, 8 surveys, 6.5 days, 1 person & & $\mathbf{1 8 1 , 5 3 6}$ \\
\hline \multirow{2}{*}{ TAI-transect } & ATV & 2 & 15,000 \\
& Heavy and light drag & 400 & 30,000 \\
& Field work, 8 surveys, 5 days, 4 people & 400 & 61,440 \\
\hline Total & Data curation, 8 surveys, 1 hour, 1 person & 8 & 48 & 384 \\
\hline
\end{tabular}

\section{Discussion}

Track counts proved to be cheaper to implement and more effective at detecting feral cats, especially when cat density was very low. Feral cats typically have a low probability of detection per night by cameras [29], possibly because each camera has a field of view of $40^{\circ}$ by $30.5 \mathrm{~m}$ [51] and hence surveys a maximum $320 \mathrm{~m}^{2}$. Reconyx cameras are designed to capture larger species such as deer (Cervidae) [51]. Feral cats are smaller and less likely to be detected when $30 \mathrm{~m}$ from the camera. An array of 130 camera-traps used over 10 nights, surveys approximately $417,846 \mathrm{~m}^{2}$. In contrast, $100 \mathrm{~km}$ of track counts on $4 \mathrm{WD}$ tracks approximately $3 \mathrm{~m}$ wide over four nights, surveys approximately 1,200,000 $\mathrm{m}^{2}$.

On Matuwa, the low probability of detecting feral cats via cameras meant that during two surveys (post-trapping survey of 2020 and post-baiting period of 2021) zero cats were detected and therefore no estimate of cat activity or population density could be derived. Given that both surveys occurred after the implementation of feral cat management actions we could make a type 1 error by falsely concluding that we had removed all feral cats from the property. Use of a second method of detecting cats prevented that erroneous conclusion.

In 2018, data from camera-traps suggested that leg-hold trapping increased the number of feral cat detections and hence may have increased the abundance of feral cats on the property. Similarly, other studies have detected a net positive effect on cat detections following the use of toxic baits [52]. In eastern Australia this nonsensical result was attributed to a significant reduction in cat activity at a paired unbaited site, which biased model outputs [52]. We attribute our increased number of feral cat detections to increased activity in feral cats, which were not removed by our management actions and may have been expanding their territories and seeking sign of conspecifics, as a result of neighbouring individuals being removed and the use of scent-based lures at camera-traps. The use of a second method of detecting cats prevented us from drawing a flawed conclusion from our 2018 data. No lures are used during track counts.

The use of multiple monitoring systems for feral cats is advisable, particularly in eradication programs either on islands or within fenced areas, especially as the population declines to low numbers. Multiple monitoring systems were crucial during the eradication 
of feral cats from Dirk Hartog Island off the coast of Western Australia where the last cat was not recorded on camera, but its sign was observed on a track transect [53]. Evidence of this cat sign resulted in deployment of traps in that area and the subsequent removal of the last cat. Where the soil substrate is not sand, and track counts are difficult to implement, alternative monitoring techniques, such as importing sand to make sandpads $[22,54]$ and/or deployment of hair snares [55], could be used to complement and verify data from camera-traps.

During trapping in 2020, no cats in the 0 to 1 age class were captured suggesting that the baiting program in 2020 had a significant impact on this age class. Prior studies have concluded that juvenile and female cats are more susceptible to toxic baits as they have higher energy requirements [31]. Our data seem to support this hypothesis. Future research should continue to monitor the demographics of the feral cat population because consistent loss of juveniles to baiting would confirm that any recovery in the feral cat population at Matuwa is a result of immigration from neighbouring properties.

Ecosystems are spatially and temporally dynamic. The abundance of fauna is a response to dynamic abiotic (e.g., rainfall) and biotic (e.g., abundance of food) conditions. It is difficult to ensure that an experimental design, with sufficient power, replicates and control treatments, is applied to research that occurs at a landscape-scale [56]. We used a study design that consists of repeated before/after sampling at a single site [57]. Two potential control sites for Matuwa were discarded: Kurrara Kurrara, a property to the north has considerably more salt lake country, which feral cats rarely use [31], and considerably more feral herbivores [58]; Jundee, a property to the west, has a similar habitat assemblage but is managed as a pastoral lease and mine site and hence offers potentially confounding variables at a landscape-scale. Likewise, other neighbouring properties that should experience sufficiently similar climatic variables are functioning cattle stations with potentially confounding variables. Sampling designs that use only a single control site to contrast against a single potentially impacted site (BACI) may be confounded with any pre-existing cause of variability between the two locations [57]. Comparing a single year of Eradicat $\AA$ baiting in a National Park to a cattle station with only 30 replicates for calculating a relative abundance of cats is inappropriate as it is unlikely to be statistically robust given the variation in management regimes [59]. If typical climatic conditions are maintained throughout the experiment, a large number of survey replicates are implemented, multiple monitoring techniques are used, and researchers carefully consider the ecological relationships among species, then reasonable inferences can be drawn from repeated before/after sampling at a single site with a pulse disturbance [57] such as baiting.

We caution researchers against the use of single-season before/after sampling experiments without careful consideration of relevant ecological relationships and wider temporal and spatial context or the use of alternative methods of monitoring feral cats that may corroborate results. Wysong et al. [28], for example, concluded that annual aerial baiting for feral cats was more effective at reducing the wild dog population than the feral cat population, and that the reduction in wild dogs had allowed an increase in the abundance of kangaroos [28] but did not consider the variation in timing of breeding behaviour and response to environmental conditions that these species may exhibit when interpreting their results. They could have used data presented in their other work [60] to assess the validity of their results. Two survey methods, track counts [61] and mortality of cats with GPS collars [60], concluded that aerial baiting reduced relative cat abundance by $61 \%$ [61] and 66\% [60], whereas camera-traps and occupancy analysis found an approximately $15 \%$ reduction in relative cat abundance [28].

\section{Conclusions}

After many years of research, we conclude that feral cats are both difficult to manage and harder to monitor. We recommend that at least two methods of monitoring cats be implemented to prevent inaccurate conclusions. Ideally, BACI designs are likely to be more informative where multiple control sites with a similar management history are 
available. We recommend an integrated pest management framework in designing feral cat management programs using both toxic baits and trapping/control methods.

Funding: This work was supported by the Chevron Gorgon Barrow Island Threatened and Priority Species Translocation Program, and the Western Australian Department of Biodiversity, Conservation and Attractions.

Acknowledgements: We express gratitude to all the people who contributed to the management of Matuwa: Tarlka Matuwa Piarku Aboriginal Corporation, the Matuwa and Kurrara Kurrara Rangers, the Lorna Glen Homestead Caretakers, the DBCA Goldfields Regional Staff, and numerous volunteers. Two Department of Biodiversity Conservation and Attractions Animal Ethics Permits (2015-39 and 2018-12) were granted for this project.

Author Contributions:Conceptualization, C.A.L and D.A; Methodology, D.A., N.H., M.O., K.N., A.J.; Formal Analysis, C.A.L.; Resources, M.O., N.H.; Data Curation, K.N., AJ; Writing - Original Draft Preparation, C.A.L., D.A.; Writing - Review \& Editing, C.A.L., D.A., K.N., A.J., M.O., N.H.; Visualization, C.A.L.; Supervision, D.A.; Project Administration, C.A.L.; Funding Acquisition, C.A.L.

Data Availability Statement: Data used in this study are available for download on Dryad ("Uploaded upon acceptance of the manuscript"; doi:).

\section{References}

Conflicts of Interest: The authors declare no conflict of interest.

1. Garrard, G.E.; Kusmanoff, A.M.; Faulkner, R.; Samarasekara, C.L.; Gordon, A.; Johnstone, A.; Peterson, I.R.; Torabi, N.; Wang, Y.; Bekessy, S.A. Understanding Australia's national feral cat control effort. Wildl. Res. 2020, 47, 698-708.

2. $\quad$ Legge, S.; Murphy, B.P.; McGregor, H.; Woinarski, J.C.Z.; Augusteyn, J.; Ballard, G.; Baseler, M.; Buckmaster, T.; Dickman, C.R.; Doherty, T.; et al. Enumerating a continental-scale threat: how many feral cats are in Australia? Biol. Conserv. 2017, 206, 293-303.

3. Doherty, T.S.; Dickman, C.R.; Johnson, C.N.; Legge, S.M.; Ritchie, E.G.; Woinarski, J.C.Z. Impacts and management of feral cats Felis catus in Australia. Mamm. Rev. 2017, 47, 83-97.

4. Sims, V.; Evans, K.L.; Newson, S.E.; Tratalos, J.A.; Gaston, K.J. Avian assemblage structure and domestic cat densities in urban environments. Divers. Distrib. 2008, 14, 387-399, doi:10.1111/j.14724642.2007.00444.x.

5. Medina, F.M.; Bonnaud, E.; Vidal, E.; Tershy, B.R.; Zavaleta, E.; Donlan, C.J.; Keitt, B.; Corre, M.; Horwath, S.; Nogales, M. A global review of the impacts of invasive cats on island endangered vertebrates. Glob. Rev. Biol. 2011, 17, 3503-3510.

6. Smith, A.P.; Quin, D.G. Patterns and causes of extinction and decline in Australian conilurine rodents. Biol. Conserv. 1996, 77, 243-267.

7. Risbey, D.A.; Calver, M.C.; Short, J.; Bradley, J.S.; Wright, I.W. The impact of cats and foxes on the small vertebrate fauna of Heirisson Prong, Western Australia. II. A field experiment. Wildl. Res. 2000, 27, 223-235.

8. Pimentel, D. Environmental and economic costs of vertebrate species invasions into the United States. In Proceedings of the Managing Vertebrate Invasive Species: Proceedings of an Internatioal Symposium; Witmer, G.W., Pitt, W.C., Fagerstone, K.A., Eds.; USDA National Wildlife Research Center: Fort Collins, CO, 2007; pp. 2-8. 
9. Stelzer, S.; Basso, W.; Silván, J.B.; Ortega-Mora, L.M.; Maksimov, P.; Gethmann, J.; Conraths, F.J.; Schares, G. Toxoplasma gondii infection and toxoplasmosis in farm animals: risk factors and economic impact. Food Waterborne Parasitol. 2019, 15, e00037.

10. Moseby, K.E.; Read, J.L.; Paton, D.C.; Copley, P.; Hill, B.M.; Crisp, H.A. Predation determines the outcome of 10 reintroduction attempts in arid South Australia. Biol. Conserv. 2011, 144, 2863-2872.

11. Hardman, B.; Moro, D.; Calver, M. Direct evidence implicates feral cat predation as the primary cause of failure of a mammal reintroduction programme. Ecol. Manag. Restor. 2016, 17, 152-158.

12. Short, J. Predation by feral cats key to the failure of a long-term reintroduction of the western barred bandicoot (Perameles bougainville). Wildl. Res. 2016, 43, 38-50.

13. Priddel, D.; Wheeler, R. An experimental translocation of brush-tailed bettongs (Bettongia penicillata) to western New South Wales. Wildl. Res. 2004, 31, 421-432.

14. Fischer, J.; Lindenmayer, D.B. An assessment of the published results of animal relocations. Biol. Conserv. 2000, 96, 1-11, doi:10.1016/S0006-3207(00)00048-3.

15. McKenzie, N.L.; Burbidge, A.A.; Baynes, A.; Brereton, R.N.; Dickman, C.R.; Gordon, G.; Gibson, L.A.; Menkhorst, P.W.; Robinson, A.C.; Williams, M.R.; et al. Analysis of factors implicated in the recent decline of Australia's mammal fauna. J. Biogeogr. 2007, 34, 597-611.

16. Gosling, L.; Stavisky, J.; Dean, R. What is a feral cat? Variation in definitions may be associated with different management strategies. J. Feline Med. Surg. 2013, 15, 759-764.

17. Stokeld, D.; Frank, A.S.K.; Hill, B.; Choy, J.L.; Mahney, T.; Stevens, A.; Young, S.; Rangers, D.; Rangers, W.; Gillespie, G.R. Multiple cameras required to reliably detect feral cats in northern Australian tropical savanna: an evaluation of sampling design when using camera traps. Wildl. Res. 2016, 42, 642-649. 18. Moseby, K.E.; Peacock, D.E.; Read, J.L. Catastrophic cat predation: a call for predator profiling in wildlife protection programs. Biol. Conserv. 2015, 191, 331-340.

19. Lancia, R.A.; Kendall, W.L.; Pollock, K.H.; Nichols, J.D. Estimating the number of animals in wildlife populations. In Techniques for Wildlife Investigations and Management; Braun, C.E., Ed.; The Wildlife Society: Bethesda, Maryland, 2005; pp. 106-153.

20. McGregor, H.W.; Hampton, J.O.; Lisle, D.; Legge, S. Live-capture of feral cats using tracking dogs and darting, with comparisons to leg-hold trapping. Wildl. Res. 2016, 43, 313-322.

21. Rees, M.W.; Pascoe, J.H.; Wintle, B.A.; Le Pla, M.; Birnbaum, E.K.; Hradsky, B.A. Unexpectedly high densities of feral cats in a rugged temperate forest. Biol. Conserv. 2019, 239, doi:10.1016/j.biocon.2019.108287.

22. Reddiex, B.; Forsyth, D.M.; McDonald-Madden, E.; Einoder, L.D.; Griffioen, P.A.; Chick, R.R.; Robley, A.J. Control of pest mammals for biodiversity protection in Australia. I. Patterns of control and monitoring. Wildl. Res. 2006, 33, 691-709.

23. Lohr, C.A.; Cox, L.J.; Lepczyk, C.A. Costs and benefits of trap-neuter-release and euthanasia for removal of urban cats in Oahu, Hawaii. Conserv. Biol. 2013, 27, 64-73.

24. Cowen, S.; Clausen, L.; Algar, D.; Comer, S. Using Genetics to Evaluate the Success of a Feral Cat (Felis catus) Control Program in North-Western Australia. Animals 2019, 9, 1050.

25. McGregor, H.W.; Legge, S.; Jones, M.E.; Johnson, C.N. Extraterritorial hunting expeditions to intense fire scars by feral cats. Sci. Rep. 2016, 6, 1-7.

26. Moseby, K.E.; Letnic, M.; Blumstein, D.T.; West, R. Understanding predator densities for successful co-existence of alien predators and threatened prey. Austral Ecol. 2019, 44, 409-419. 
27. Read, J.L.; Bengsen, A.J.; Meek, P.D.; Moseby, K.E. How to snap your cat: optimum lures and their placement for attracting mammalian predators in arid Australia. Wildl. Res. 2015, 42, 1-12.

28. Wysong, M.L.; Iacona, G.D.; Valentine, L.E.; Morris, K.; Ritchie, E.G. On the right track: placement of camera traps on roads improves detection of predators and shows non-target impacts of feral cat baiting. Wildl. Res. 2020, doi:10.1071/WR19175.

29. Moore, H.A.; Valentine, L.E.; Dunlop, J.A.; Nimmo, D.G. The effect of camera orientation on the detectability of wildlife: a case study from north-western Australia. Remote Sens. Ecol. Conserv. 2020, 6, $546-556$.

30. Edwards, G.P.; De Preu, N.D.; Shakeshaft, B.J.; Crealy, I. V An evaluation of two methods of assessing feral cat and dingo abundance in central Australia. Wildl. Res. 2000, 27, 143-149.

31. Lohr, C.A.; Algar, D. Managing feral cats through an adaptive framework in an arid landscape. Sci. Total Environ. 2020, 720, 137631.

32. Lohr, C. Twelve years of rangelands restoration: reintroduction of native mammals to Matuwa (exLorna Glen pastoral lease): SPP 2012-024; Perth, Western Australia, Australia, 2019;

33. Lohr, C.; Dziminski, M.; Dunlop, J.; Miller, E.; Morris, K. The reintroduction of bilbies (Macrotis lagotis) to Matuwa, an Indigenous Protected Area in Western Australia. Rangel. Ecol. Manag. 2021, 78, 6778.

34. Palmer, B.; Valentine, L.; Lohr, C.; Daskalova, G.; Hobbs, R. Burrowing by translocated boodie (Bettongia lesueur) populations alters soils but has limited effects on vegetation. Ecol. Evol. 2021, 11, 25962615.

35. Lohr, C.A.; Nilsson, K.; Sims, C.; Dunlop, J.; Lohr, M.T. Habitat selection by vulnerable golden bandicoots in the arid zone. Ecol. Evol. 2021, doi.org/10.1002/ece3.7875.

36. Algar, D.; Onus, M.; Hamilton, N. Feral cat control as part of rangelands restoration at Lorna Glen (Matuwa), Western Australia: the first seven years. Conserv. Sci. West. Aust. 2013, 8, 367-381.

37. Denny, E.; Dickman, C. Review of cat ecology and management strategies in Australia; Invasive Animals Cooperative Research Centre: Canberra, Australia, 2010;

38. Moseby, K.E.; Hill, B.M.; Read, J.L. Arid Recovery - A comparison of reptile and small mammal populations inside and outside a large rabbit, cat and fox-proof exclosure in arid South Australia. Austral Ecol. 2009, 34, 156-169, doi:10.1111/j.1442-9993.2008.01916.x.

39. Beard, J.S.; Beeston, G.R.; Harvey, J.M.; Hopkins, A.J.M.; Shepherd, D.P. The vegetation of Western Australia at the 1: 3,000,000 scale. Explanatory memoir. Conserv. Sci. West. Aust. 2013, 9, 1-152.

40. Mabbutt, J. Land systems of the Wiluna-Meekatharra area, Western Australia 1963.

41. Algar, D.; Angus, G.J.; Williams, M.R.; Mellican, A.E. Influence of bait type, weather and prey abundance on bait uptake by feral cats (Felis catus) on Peron Peninsula, Western Australia. Conserv. Sci. West. Aust. 2007, 6 .

42. Algar, D.; Burrows, N.D. Feral cat control research : Western Shield review — February 2003. Conserv. Sci. West. Aust. 2004, 5, 131-163.

43. Jones, E.; Coman, B.J. Ecology of the feral cat, Felis catus (L.), in south-eastern Australia II.* Reproduction. Wildl. Res. 1982, 9, 111-119.

44. Farrell, T. Geological Survey of Western Australia, Wiluna WA Sheet SG51-9 1999.

45. Kays, R.; Tilak, S.; Kranstauber, B.; Jansen, P.A.; Carbone, C.; Rowcliffe, M.J.; Fountain, T.; Eggert, J.; He, Z. Monitoring wild animal communities with arrays of motion sensitive camera traps. Int. J. Res. 
Rev. Wirel. Sens. Networks 2010, 1, 19-29.

46. Wysong, M.L. Predator ecology in the arid rangelands of Western Australia: spatial interactions and resource competition between an apex predator, the dingo Canis dingo, and an introduced mesopredator, the feral cat Felis catus, The University of Western Australia Ph.D Thesis, 2016.

47. Ivan, J.S.; Newkirk, E.S. CPW Photo Warehouse: a custom database to facilitate archiving, identifying, summarizing and managing photo data collected from camera traps. Methods Ecol. Evol. 2016, 7, 499-504. 48. Kays, R.; Costello, R.; Forrester, T.; Baker, M.C.; Parsons, A.W.; Kalies, E.L.; Hess, G.; Millspaugh, J.J.; McShea, W. Cats are rare where coyotes roam. J. Mammal. 2015, 96, 981-987.

49. Brooks, M.; Kristensen, K.; van Benthem, K.; Magnusson, A.; Berg, C.; Nielsen, A.; Skaug, H.; Maechler, M.; Bolker, B. glmmTMB Balances Speed and Flexibility Among Packages for Zero-inflated Generalized Linear Mixed Modeling. $R$ J. 2017, 9, 378-400.

50. Mazerolle, M. AICcmodavg v2.3-1 Available online: https://www.rdocumentation.org/packages/AICcmodavg/versions/2.3-1 (accessed on Feb 17, 2021). 51. Inc., R. Reconyx Hyperfire high performance cameras: Instruction manual Available online: http://images.reconyx.com/file/HyperFireManual.pdf (accessed on Oct 22, 2021).

52. Fancourt, B.A.; Harry, G.; Speed, J.; Gentle, M.N. Efficacy and safety of Eradicat ${ }^{2}$ feral cat baits in eastern Australia: population impacts of baiting programmes on feral cats and non-target mammals and birds. J. Pest Sci. (2004). 2021, 1-18.

53. Algar, D.; Johnston, M.; Tiller, C.; Onus, M.; Fletcher, J.; Desmond, G.; Hamilton, N.; Speldewinde, P. Feral cat eradication on Dirk Hartog Island, Western Australia. Biol. Invasions 2020, 22, 1037-1054.

54. Johnston, M.; Algar, D.; O’Donoghue, M.; Morris, J. Field efficacy of the Curiosity feral cat bait on three Australian islands. Veitch, CR; Clout, MN Towns, DR 2011, 182-187.

55. Hanke, P.U.; Dickman, C.R. Sniffing out the stakes: hair-snares for wild cats in arid environments. Wildl. Res. 2013, 40, 45-51.

56. Palmer, R.; Anderson, H.; Richards, B.; Craig, M.D.; Gibson, L. Does aerial baiting for controlling feral cats in a heterogeneous landscape confer benefits to a threatened native meso-predator? PLoS One 2021, 16, e0251304.

57. Underwood, A.J. Beyond BACI: experimental designs for detecting human environmental impacts on temporal variations in natural populations. Mar. Freshw. Res. 1991, 42, 569-587.

58. GNRBA Post activity report GNRBA Wiluna aerial shoot 20-28TH March 2021; Goldfields Nullabor Rangelands Biosecurity Association: Kalgoorlie, Western Australia, 2021;

59. Fancourt, B.A.; Augusteyn, J.; Cremasco, P.; Nolan, B.; Richards, S.; Speed, J.; Wilson, C.; Gentle, M.N. Measuring, evaluating and improving the effectiveness of invasive predator control programs: Feral cat baiting as a case study. J. Environ. Manage. 2021, 280, 111691.

60. Wysong, M.L.; Hradsky, B.A.; Iacona, G.D.; Valentine, L.E.; Morris, K.; Ritchie, E.G. Space use and habitat selection of an invasive mesopredator and sympatric, native apex predator. Mov. Ecol. 2020, 8, 1-14. 61. Burrows, N.; Liddelow, G. Lorna Glen Introduced Predator Control; Western Australia Department of Parks and Wildlife: Perth, 2013; 